\title{
O OVO E A GALINHA \\ Estudo do enquadramento e da recepçáo da cobertura jornalística no pleito de 2014
}

\section{Joáo Feres Júnior}

Instituto de Estudos Sociais e Políticos da Universidade do Estado do Rio de Janeiro (Iesp-Uerj), Rio de Janeiro - RJ, Brasil. E-mail: jferes@iesp.uerj.br

\section{Luciana Fernandes Veiga}

Universidade Federal do Estado do Rio de Janeiro (Unirio), Rio de Janeiro - RJ, Brasil. E-mail: luciana.veiga@unirio.br

\section{Ednaldo Ribeiro}

Universidade Estadual de Maringá (UEM), Maringá - PR, Brasil. E-mail: earibeiro@uem.br

DOI: $10.1590 / 339809 / 2018$

\section{Introdução}

A atual crise política que assola o país trouxe à tona do debate público, mais uma vez, a importância da mídia para o funcionamento da democracia representativa. Na verdade, a comunicação tem papel de destaque em todas as principais vertentes da teoria democrática, agregacionista (Downs, 1957), deliberativa (Habermas, 1996) e participativa (Pateman, 1970), ainda que de maneira indireta na última. Contudo, nas análises mais empiricamente orientadas do funcionamento democrático feitas por sociólogos e cientistas políticos, o tema da comunicação e da mídia raramente aparece - com exceção dos estudos de mídia e política. É preciso dizer também que a maior parte destes estudos

Artigo recebido em 18/08/2016

Aprovado em 20/09/2017 se concentra na análise do comportamento da mídia em períodos eleitorais, com algumas exceçôes, como a literatura mais recente sobre mídias sociais, que é em grande medida produzida em departamentos de Comunicação e não de Sociologia ou de Ciência Política.

A análise do comportamento da mídia em períodos eleitorais, por seu turno, assim como algumas outras modalidades de estudos de mídia, é presa de certo paradoxo metodológico. A maior parte dos autores opta por circunscrever os esforços deles à interpretação sistemática do conteúdo e forma da comunicação midiática, ou seja, os autores estudam a emissão. Ao fazê-lo, os estudiosos assumem haver, na prática, algum efeito de mídia, ou seja, a recepção efetiva das mensagens, ainda que tal recepção nunca seja, de fato, comprovada.

Os estudos de recepção são bem mais raros e podem ser de duas modalidades: qualitativos ou quantitativos, ambos com virtudes e problemas. Os 
qualitativos conseguem aprofundar bastante o conhecimento das diferentes respostas que as pessoas dão aos conteúdos veiculados, mas os resultados de tais estudos náo podem ser tomados como representativos da população em geral devido à própria natureza dessa metodologia. Já os surveys são capazes de gerar dados estatisticamente significativos, mas não são apropriados para o acompanhamento passo a passo - da recepção da mensagem e do processo de persuasão da audiência.

O presente estudo propóe uma solução indireta para as aporias que marcam esse campo, ao combinar dados de diversas fontes e abordagens de diferentes disciplinas. A partir de uma discussão com a literatura sobre o voto econômico, advinda da ciência política, testamos a hipótese de que a exposição a determinados meios de comunicação está correlacionada à avaliação da economia e à aprovação do governo federal. Para tal, aplicamos modelos logísticos multinomiais, usando como variáveis dependentes a "satisfação com o governo" e a "avaliação da economia”.

De acordo com a literatura do voto econômico, a avaliação do eleitor acerca da economia tem impacto sobre a sua adesão ao governo e sobre o seu voto em pleitos nacionais (Lewis-Beck e Stegmaier, 2008). Contudo, a avaliação retrospectiva do eleitor, mostra essa mesma literatura, não está pautada exclusivamente na variação dos índices objetivos da macroeconomia, mas outrossim (i) em aspectos do contexto institucional (Anderson, 2008; Sniderman e Levenduscky, 2008); (ii) em pré-disposições cognitivas e afetivas (Duch e Stevenson, 2008; Lau e Redlawsk, 1997); e (iii) na cobertura da imprensa (Soroka et al., 2015), entre outros fatores. Tais variáveis impactam tanto na leitura da economia quanto na responsabilização dos resultados econômicos atingidos pelo governo central.

Neste artigo, interessa-nos entender a relação existente entre a cobertura jornalística da economia, a avaliação retrospectiva da macroeconomia e a adesão ao governo federal manifesta pelos eleitores no contexto da eleição para a presidência do Brasil de 2014.

Nosso primeiro objetivo específico é identificar como se deu o agendamento da notícia econômica, considerando os conceitos de "priming" e de "enquadramento". O priming corresponde à tenta- tiva da mídia de erigir alguns assuntos como parâmetros mediante os quais as açóes de um governo ou político devem ser medidas, como por exemplo: a corrupção, o desempenho da política econômica, a segurança pública, a segurança hídrica, etc (Iyengar e Kinder, 1987). Já o conceito de enquadramento tem pelo menos duas definiçóes que nos interessam aqui. A primeira é ligada à recepção da notícia, segundo a qual o enquadramento corresponde aos esquemas mentais produzidos pela comunicação midiática no público. Já a segunda definição diz respeito às estratégias retóricas e formas por meio das quais os jornais apresentam um determinado assunto (Mendonça e Simóes, 2012). Nesse sentido do conceito, restrito àquilo que concerne à emissão, enquadrar consiste em salientar e enfatizar alguns aspectos da notícia em detrimento de outros (Entman, 1993; Gitlin, 2003), sugerindo interpretaçóes e contribuindo para que o leitor "construa simbolicamente a estrutura do mundo" (Reese et al., 2001).

No Brasil, os estudos de emissão de notícias em eleiçôes têm sido voltados para a análise dos grandes jornais impressos e do Jornal Nacional (JN), programa de notícias da TV Globo (Azevedo, 2009; Biroli e Mantovani, 2014; Porto, 2007). Uma outra característica une quase a totalidade do corpus acadêmico produzido no Brasil: o objeto de análise é a emissão, e não a recepção. $\mathrm{Na}$ literatura de estudos de mídia e política brasileira pouco se tem abordado o impacto dos textos jornalísticos na audiência, com exceção de parte do trabalho de Mauro Porto (2007). Em um dos artigos, a partir de análise de conteúdo da cobertura do Jornal $\mathrm{Na}$ cional e de propagandas eleitorais da disputa presidencial de 2002 no Brasil, Porto conclui que a exposição ao telejornal levou a audiência a aderir ao enquadramento que enfatiza a necessidade de se manter a inflação sob controle para proteger a estabilidade da economia. Tal discurso esteve muito presente no $J N$ e na campanha do entáo presidente Fernando Henrique Cardoso (Porto, 2007). Por sua vez, a exposiçáo à propaganda eleitoral levaria os eleitores a rejeitarem tal leitura na medida em que os candidatos de oposição enfatizavam problemas sociais, com foco na pobreza e na desigualdade social. Em suma, o trabalho de Porto aponta para a possibilidade de confirmação de nossa hipótese so- 
bre a existência de um efeito significativo da mídia no comportamento dos cidadãos.

O presente trabalho pretende contribuir para essa vertente inaugurada pelo trabalho de Porto, mas utilizando-se de ferramentas metodológicas e escopo diferentes. Buscamos estabelecer associaçóes entre a cobertura da imprensa e o comportamento político de seu público. Para isso, em um primeiro momento, é apresentada a análise de conteúdo dos quality newspapers, ${ }^{1}$ sejam eles: Folha de S. Paulo, $O$ Estado de S. Paulo e O Globo, bem como do programa de notícias televisivo Jornal Nacional, a fim de avaliar como cobriram o assunto economia no período da campanha eleitoral de 2014. A partir de tal análise de conteúdo, serão definidas as hipóteses sobre o comportamento político do público (audiência/leitores) quanto à avaliação do governo federal e à avaliação específica da economia. Na sequência, analisaremos como os respectivos públicos de cada meio (JN, FSP e $O$ Globo) avaliavam o governo federal e a economia a partir do resultado de um survey. A expectativa é que haja associação entre a intensidade do viés da cobertura da economia do veículo com o viés da percepção sobre o assunto na audiência do meio.

Interessa-nos verificar o modo pelo qual o conteúdo da mídia pode ter influenciado a avaliação da economia. Sabemos que o efeito pode acontecer não apenas em um sentido. Soroka et al. (2015) mostra que o sentimento da opinião pública sobre a economia pode influenciar a cobertura jornalística em si. Isso faria sentido, segundo o autor, na medida em que os jornalistas tendem a se pensar como representantes da população, buscando refletir as suas preocupaçóes.

Este artigo segue uma perspectiva, já bem explorada pela literatura, ao apostar na relevância da mediação para a percepção do estado da economia e, por conseguinte, para a formação da opinião política dos eleitores. Em outras palavras, a mídia teria um papel importante na formação da avaliação da economia e na taxa de adesão ao governo (Soroka et al., 2015). No que diz respeito à eleição presidencial de 2014, dois estudos defenderam que tal tese acerca da influência da mídia não se verificou. A partir de um modelo com quinze variáveis que cobrem explicaçóes contextuais, socio- demográficas e de identidade política para a escolha eleitoral nos dois turnos de 2014, Amaral e Ribeiro (2015) concluíram que o voto foi retrospectivo, mas não se restringiu "à avaliação do cenário econômico ou à participação direta nos programas de transferência de renda” . Veiga e Ross, por sua vez, demonstraram que a avaliaçáo da economia naquela disputa estava associada à identidade partidária e à ideologia e náo ao conhecimento da realidade objetiva da economia (Veiga e Ross, 2016). No presente trabalho, propomos avançar um passo no sentido de deslindar os mecanismos formadores de tais percepções, ao incluir a questão da mediação da informação na hipótese explicativa.

Utilizamos dois bancos de dados. O primeiro contém dados quantitativos sobre a cobertura de jornais impressos e do telejornal Jornal Nacional no ano de 2014. O segundo banco advém da "Pesquisa Brasileira de Mídia”, consulta quantitativa nacional realizada pela Secretaria de Comunicação da Presidência da República, também em 2014. A ferramenta de análise estatística utilizada é a regressão multinominal, na qual as variáveis dependentes serão a "satisfação com o governo" e a "avaliação retrospectiva sociotrópica da economia”. As variáveis independentes serão a "condição de audiência do JN", "ler o jornal a Folha de S. Paulo" e "ler o jornal O Globo". Foram adicionados como controles os seguintes atributos: sexo, idade, escolaridade, renda familiar, religião e região de moradia.

Além de contribuir para o debate da associação entre a cobertura da imprensa e o comportamento político, o trabalho avança na tradição de estudos de enquadramento adotados pelo Jornal Nacional, durante campanhas eleitorais. Tal programa foi escolhido como o objeto de estudo desta pesquisa por se tratar do telejornal com a maior audiência no país e por ser objeto frequente de análise por parte dos estudos de Comunicação e Política. Já a Folha de $S$. Paulo e $O$ Globo foram escolhidos por se tratar de quality newspapers nacionais, com maiores tiragens.

$\mathrm{O}$ artigo foi organizado da seguinte maneira: na próxima seção, faremos uma exposição do contexto eleitoral de 2014. Na sequência, apresentaremos a revisão da teoria do voto econômico e da abordagem do enquadramento com a finalidade de situar as hipóteses de nosso estudo. Logo depois, 
exporemos uma análise de conteúdo da cobertura dos jornais e do Jornal Nacional no período eleitoral. Na seção seguinte, mostraremos os resultados da análise da associação entre a exposição ao telejornal e aos diários impressos Folha de $S$. Paulo e $O$ Globo e a avaliação que os eleitores fazem do governo federal e do desempenho da economia no país. Por fim, discutiremos os resultados da análise apontando para agendas de possíveis pesquisas futuras.

\section{O Contexto Eleitoral de 2014}

O contexto do estudo é a eleição presidencial de 2014 no Brasil. A presidente Dilma Rousseff (PT), candidata à reeleição, iniciou o período oficial de veiculação de propaganda eleitoral com $1 / 3$ do eleitorado avaliando o seu governo como positivo (Pesquisa Ibope, de 15 de agosto). Na época, a desaceleraçáo do crescimento econômico e o aumento da taxa de inflação eram notados. No plano político, havia denúncias de corrupção e má gestão dos recursos públicos, durante a preparação para a Copa do Mundo 2014, bem como ocorreu a prisão de lideranças do PT, em decorrência do processo do "Mensalão". Todos esses eventos foram fartamente noticiados pela grande mídia brasileira.

A despeito da agenda fortemente negativa, a presidente Dilma conseguiu, no decorrer da veiculação da propaganda eleitoral até as portas do primeiro turno, aumentar a sua avaliaçáo positiva para $39 \%$ e reduzir a sua avaliação negativa para $25 \%$ (Pesquisa Ibope, de $1^{\circ}$ de outubro). No segundo turno da eleição, a avaliação positiva da presidente alcançou $46 \%$ e a negativa caiu para 23\% (Pesquisa Ibope, de 25 de outubro).

Os dois desafiantes principais de Dilma eram Aécio Neves (PSDB) e Eduardo Campos (PSB). $\mathrm{Na}$ véspera do início da veiculação da propaganda eleitoral, Dilma contava com 38\% das intençōes de voto; Aécio atingia 22\% e Eduardo Campos $8 \%$ das intenções de voto (Pesquisa Ibope, de 21 julho). Em 13 de agosto, Campos veio a falecer em um acidente de avião em Santos, São Paulo. Marina Silva, vice-candidata na chapa do PSB, assumiu a frente da chapa do partido na campanha. Em um período de cinco dias, ela alcançou 29\% das intençôes de voto, superando Aécio Neves e ficando apenas 5 pontos aquém da presidente Dilma Rousseff. Na simulação de segundo turno, Marina venceria Aécio e Dilma. O momento coincidiu com o agravamento das denúncias contra o PT, na chamada "Operação Lava Jato”, que envolvia corrupção na Petrobrás. Contudo, a candidatura de Marina foi enfraquecida em meio a críticas de seus adversários às trajetória, pessoa e proposta de governo da candidata. No início do segundo turno, Aécio Neves cresceu nas intençóes de voto e chegou a assumir o favoritismo nas pesquisas. Mas esse crescimento não foi suficiente para vencer a disputa, seja pelos próprios erros do candidato ou pela maior eficiência da campanha movida pela chapa da situação. Aécio não conseguiu consolidar a sua liderança e Dilma venceu o segundo turno por pequena margem de votos.

Passemos à análise da realidade econômica que antecedeu a disputa presidencial de 2014. As taxas de desemprego e de inflação oficiais levantadas pelo Instituto Brasileiro de Geografia e Estatística (IBGE) foram relativamente estáveis, com variaçôes mensais muito semelhantes às que vinham acontecendo em 2013 e 2014 . A taxa de desemprego variou entre $6,2 \%$ e $7,2 \%$ nos doze meses que antecederam a disputa. A inflação variou da taxa mensal mais alta 0,95\%, em dezembro de 2013, à taxa mais baixa $0,01 \%$, em julho de 2014 . Todavia, a economia experimentava desaceleração do crescimento: depois do Produto Interno Bruto (PIB) variar em 2,7\%, em 2013, ele variou 0,1\% em 2014.

\section{Revisão teórica}

Uma ampla literatura sobre o voto econômico dá lastro a já famosa advertência: It's the economy, stupid! O desenvolvimento de tal vertente é tributário da teoria econômica da democracia de Anthony Downs (1957), ainda que não por caminhos tão óbvios como a coincidência do uso do termo "econômico" possa sugerir. Downs tem a noção de interesse individual balizado pelo modelo do comportamento racional como o elemento fundamental da teoria por ele sustentada. Assim, a política econômica do governo e o estado geral da economia são informações cruciais para o eleitor maximizador de 
seu bem-estar em uma sociedade capitalista democrática e liberal. $\mathrm{Ou}$, como afirma um comentador, se os eleitores não estão usando informaçôes sobre a economia de modo racional, então, toda teoria de Downs estaria ameaçada (Duch, 2007).

A teoria derivada do voto econômico começou a tomar corpo com os trabalhos de Gerald H. Kramer (1971), John Ferejohn (1986) e Morris P. Fiorina (1981). Estudos empíricos da influência da informação econômica no comportamento eleitoral, quase que exclusivamente baseados na experiência do presidencialismo norte-americano, foram produzidos já na década de 1970 ( Kramer, 1971). Parte da literatura se dedicou a estimar o impacto da percepção da economia na popularidade do presidente, que, por sua vez, afeta a chance de reeleição (Lanoue, 1987; Norpoth et al., 1991; Tufte, 1975). Trabalhos que discutem o impacto do voto econômico sobre as eleições parlamentares não mostraram resultados tão promissores (Alesina et al., 1993; Erikson, 1990; Marra e Ostrom, 1989), mas, no que toca as eleições presidenciais, o voto econômico é um consenso na academia norte-americana.

Os estudos individuais do voto econômico em outros países mostraram resultados desiguais (Goodhart e Bhansali, 1970; Lafay, 1977; Lewis-Beck, 1980), mas, recentemente, análises multinacionais, com grande número de casos $(\mathrm{N})$, têm confirmado a existência generalizada do voto econômico, ainda que apresentando variaçóes significativas entre os países ou mesmo ao longo da história do mesmo país (Duch e Stevenson, 2008). A maneira pela qual os autores explicam as variaçóes significativas no voto econômico é atribuí-las a outros fatores contextuais pertinentes a cada caso nacional (Duch, 2007). Entre os fatores identificados pela literatura como capazes de interferir no voto econômico, moldando, até mesmo, a percepção do clima econômico pelo eleitor, está a "politização", isto é, a simpatia declarada a partidos políticos (Duch et al., 2000; Zaller, 2004).

A literatura sobre o voto econômico não é indiferente à questão da mediação da informação que chega ao cidadão. Muitos trabalhos mostram o papel da mídia na formação da avaliação do estado da economia por parte de consumidores e eleitores (De Boef e Kellstedt, 2004; Duch e Ste- venson, 2008; Erikson et al., 2001; Nadeau et al., 1999) - mesmo que alguns autores tenham tentado negar essa efeito da mídia (Haller e Norpoth, 1997). Suzanna Boef e Paul Kellsted (2004) veem a influência da mídia sobre a avaliação da economia como indireta, condicionada à avaliação da política econômica do presidente. Já Richard Nadeau et al. (1999) pretende mostrar um efeito direito da cobertura sobre a avaliação da economia. A despeito dessas diferenças, há uma tendência geral entre esses autores de destacar a pré-disposição da mídia a intensificar a sua cobertura em períodos de crise (Su, 2008) e de responsabilização dos ministros a cargo da política econômica (Brug et al., 2007; Duch e Stevenson, 2008).

É importante ressaltar que esse grupo de autores não reconhece um papel ativo da grande mídia, o de enviesar ideologicamente a cobertura para além da tendência comercial de explorar fatos surpreendentes e situaçôes críticas (Duch e Stevenson, 2008). Ou seja, a tendência da mídia a intensificar e dramatizar o noticiário econômico, segundo tais autores, tem a ver com a lógica comercial da midia: vender mais, atrair mais atenção - e não com o seu viés ideológico propriamente dito (Karel-Jan et al., 2004).

Há, contudo, uma parte crescente da literatura que tem tratado da questão do viés midiático, evitando além disso o foco exclusivo em períodos eleitorais. Deborah J. Blood e Peter C. B. Phillips, por exemplo, comparam as séries temporais da valência da cobertura midiática da economia, da percepção popular da economia, do estado real da economia e da popularidade do presidente. Utilizando a autoregressão vetorial e o teste de Granger para estabelecer anterioridade causal, os autores concluem que manchetes relatando recessão econômica influenciam o sentimento dos consumidores em relação à economia. Também encontram uma tendência do New York Times de se opor ao crescimento da popularidade do presidente ao aumentar a cobertura negativa da economia (Blood e Phillips, 1995).

Em estudo similar, Valentino Larcinese, Riccardo Puglisi e James M. Snyder Jr. substituem a popularidade do presidente pelas variáveis "partido do presidente" e "apoio do jornal" e encontram resultados consistentes de viés na cobertura da economia de jornais democratas contra os candidatos republica- 
nos, se comparados a jornais que declaram apoio aos republicanos (Larcinese et al., 2011). Outro trabalho semelhante encontra não somente disparidade entre o real estado da economia e o conteúdo das notícias sobre economia, mas também influência da cobertura na avaliação do público e, por fim, viés negativo da cobertura da economia durante a campanha de George Bush pai à presidência (Goidel e Langley, 1995). Um resultado semelhante foi obtido por Marc J. Hetherington, ao detectar grande viés negativo da cobertura da economia na eleição de 1992, na qual Bush teve frustradas as pretensões de permanência no cargo (Hetherington, 1996).

Em suma, há um número crescente de trabalhos que analisam o volume e o tom da cobertura da mídia sobre a economia. Afinal, a imprensa tem o papel de mediador entre a situação econômica e a percepçáo do eleitor.

No Brasil, uma literatura crescente da ciência política tem se debruçado sobre a questão do voto econômico, ainda que o foco das pesquisas esteja em períodos mais recentes. As análises sobre as eleiçôes de 1994, 1998, 2002, 2006, 2010 e 2014 (Carreirão, 2002; Mendes e Venturi, 2015; Meneguello, 1994; Peixoto e Rennó, 2011) confirmam a pertinência dessa tese. Embora Amaral e Ribeiro defendam que o julgamento do desempenho do governo, no pleito de 2014, esteve dissociado da avaliação da economia do país (Amaral e Ribeiro, 2015).

Ao buscarem motivações específicas do voto econômico, Wendy Hunter e Timothy Power exploram os efeitos do programa Bolsa Família na reeleição de Lula, em 2006. Comparando os dados eleitorais das eleiçóes de 2002 e 2006, por meio de modelos de regressão multivariada, utilizando como variáveis dependentes o Índice de Desenvolvimento Humano (IDH), a renda per capita do estado, e sua suposta tradição democrática (ou oligárquica), os autores identificam uma mudança de padrão de votação no candidato petista, de uma eleição a outra, em direção aos estados mais pobres e "oligárquicos". Tal mudança, para eles, seria um resultado do voto econômico retrospectivo que premiou programas de transferência de renda do governo petista (Hunter e Power, 2007).

Em um trabalho apresentado no mesmo ano, 2007, comparando os mesmos pleitos, mas utilizan- do dados municipais, Jairo Nicolau e Vitor Peixoto também postulam ter encontrado uma relação positiva entre o voto em Lula e as variáveis econômicas, sejam elas o baixo IDH e a alta participação do município no Bolsa Família. Em outras palavras, os autores corroboram a tese do voto retrospectivo de inspiração econômica (Nicolau e Peixoto, 2007).

Os trabalhos de Cesar Zucco também confirmam essa tese, utilizando metodologia similar à de Nicolau e Peixoto, ou seja, regressão multivariada a partir de dados municipais. O autor, contudo, pretende adicionar ao efeito dos programas de transferência de renda um outro fator que ele descreve como "a regularidade empírica com que candidatos à presidência do partido no poder, no Brasil, sempre alcançam resultados melhores nas áreas menos desenvolvidas do país" (Zucco, 2008). Em artigo posterior, o autor utiliza a mesma abordagem para analisar três eleições, e chegar a mais uma reafirmação do voto econômico retrospectivo como importante explanandum do comportamento eleitoral, ainda que qualificando os efeitos supostamente passageiros e pouco politizantes dos programas de transferência de renda (Zucco, 2013).

Ao focar nos programas de transferência de renda, apresentando-os como a explicação dessa migraçáo eleitoral, esses autores assumem o fato de o eleitorado de classe média ter abandonado Lula e o partido dele como natural. Na verdade, eles apenas explicam uma parte do fenômeno, qual seja, o crescimento do eleitorado em municípios e regióes que mais recebem o benefício, mas não lidam com a explicação do comportamento da outra parte do eleitorado. Hunter e Power talvez sejam uma exceção. De fato, eles lidam, ainda que brevemente, com a questão da corrupçáo, mas resolvem o problema ao afirmar que os eleitores mais informados e educados são mais sensíveis ao assunto, ao passo que os pobres estão presos à satisfação de suas necessidades econômicas básicas. Para sustentar tal tese, afirmam que os grandes meios de comunicação têm baixa circulação e, portanto, não atingem os grotóes - uma visão simplista e equivocada do alcance da grande mídia no Brasil - e que os pobres tendem a ser mais patrimonialistas do que os brasileiros "mais educados", citando como fonte uma interpretação da PESB (Pesquisa Social Brasileira) 
feita por Alberto Almeida para uma revista não acadêmica (Hunter e Power, 2007).

Neste artigo, pretendemos ir além desse esquema explicativo que naturaliza a comunicação, tematizando diretamente o efeito de mídia sobre a formação de preferências eleitorais.

Há, contudo, outro ramo da literatura acadêmica que é relevante para o presente artigo: aquele focado na cobertura jornalística de eleiçóes, ou seja, mais propriamente no comportamento dos grandes meios de comunicação. Essa literatura ganhou impulso com a redemocratização do país, particularmente após a primeira eleição presidencial da Nova República, que já foi marcada por ativismo político da imprensa (Rubim e Azevedo, 1998). Ao longo das seguidas eleiçóes presidenciais, muitas análises foram produzidas - alias, seria uma tarefa inglória tentar citá-las todas neste curto artigo. Em uma lista, que está longe de fazer jus ao dinamismo dessa literatura, temos os trabalhos de Kucinski (1998), Luis Felipe Miguel (1999b) e Carlos Eduardo Lins da Silva (1990), abordando as eleições de 1989; os de Roseli Rossi Figueiredo (Colling, 2006), Lílian Rose Arruda (Colling, 2006) e Miguel (1999b), as de 1994; os de Azevedo (2000) e Miguel (1999a), tratando do pleito de 1998; os de Lima e Guazina (2004), Miguel (2004), Colling (2004) e Alessandra Aldé (Aldé, 2003), para o de 2002; os trabalhos de Alessandra Aldé, Gabriel Mendes e Marcus Figueiredo (2007) e Kjeld Jakobsen (2007) referem-se ao pleito de 2006, e muitos outros que não foram citados.

Entre os muitos trabalhos sobre mídia e eleiçóes, produzidos ao longo dos anos, alguns enfatizam o tratamento jornalístico da economia e os prováveis efeitos da abordagem midiática sobre o pleito. Por exemplo, em sua análise da cobertura política do Jornal Nacional, após retomar a discussão acerca da edição do debate entre Collor e Lula, às vésperas do segundo turno do pleito de 1989 , Afonso Albuquerque (2013) parte para a análise do comportamento do telejornal nas disputas presidenciais subsequentes, as de 1994 e de 1998. Nelas, o autor identifica não apenas a continuação do viés antipetista, mas também o uso do noticiário econômico para efeito político eleitoral. Segundo Albuquerque, o tratamento favorável dispensado ao
Plano Real ajudou Fernando Henrique Cardoso então ministro da fazenda do presidente Itamar Franco - a garantir a vitória no primeiro turno das eleições, em 1994. Em 1998, mais uma vez, tivemos um duelo entre Cardoso e Lula, em um contexto de aguda crise da economia brasileira. O JN, contudo, preferiu enfatizar a suposta origem internacional da crise e minimizou a responsabilidade do governo federal - então presidido pelo tucano.

Ainda que por meio de outra abordagem, Luis Felipe Miguel corrobora a tese de Albuquerque, ao notar que, no pleito de 1998 , o $J N$ não apenas despolitizou a cobertura, relegando a eleição a um assunto secundário, como evitou tematizar os efeitos mais agudos da crise econômica, como o alto desemprego, preferindo dar atenção a fait divers como os crimes, os escândalos internacionais, o nascimento da filha de Xuxa, etc (Miguel, 1999a).

Essa atitude de leniência perante a responsabilização do governo foi verificada no jornalismo econômico, de maneira mais geral, no decorrer dos mandatos de Cardoso, por Ailton Contin (2015). Ao examinar a cobertura da mídia sobre o processo de privatização de empresas estatais, durante os dois governos do peessedebista, entre 1995 e 2002, em quatro revistas brasileiras semanais de grande circulação (Veja, IstoÉ, Carta Capital e Época), o autor conclui que houve manipulação nas informaçôes referentes ao caso da Telebrás. Segundo Contin, as quatro revistas selecionadas noticiaram, predominantemente, fragmentos e versóes dos fatos condizentes à linha editorial de cada uma delas: favorável à privatização (no caso de Veja, IstoÉ e Época) ou contrária à venda da estatal de telefonia (Carta Capital). Ao deixarem de apresentar as controvérsias do processo, com argumentos favoráveis e contrários a privatização presentes na sociedade, naquele momento, as narrativas jornalísticas das revistas analisadas não contribuíram para a formação crítica e autônoma dos leitores.

A questão da economia também entrou no radar das análises da cobertura midiática da eleição de 2002, como, por exemplo, no trabalho de Fernando Azevedo (2009). Para ele, a relação entre a mídia e o PT, entre os anos 1989 e 2002, foi determinada pela tensão entre valores ideológicos antagônicos: a grande imprensa é franca adepta da economia de merca- 
do e da democracia representativa, enquanto o PT defendia uma agenda socialista e crítica à democracia representativa. Isso muda em 2002 com o deslocamento do partido para o centro político, particularmente após a Carta aos Brasileiros. Azevedo restringe a análise dele ao âmbito da mídia impressa, ressaltando que a televisão está fortemente regulada pela legislação eleitoral, o que forçaria os canais abertos a darem tratamento equilibrado nas coberturas de partidos e candidatos durante o período eleitoral.

Ainda sobre a conexão entre economia, mídia e política eleitoral, Flavia Biroli e Denise Mantovani (2014) argumentam que a Carta aos Brasileiros foi um divisor de águas na relação entre mídia e PT, pois ela metamorfoseou o partido socialista em "partido da ordem", integrado ao capitalismo de mercado e às formas correntes do fazer política. Contudo, tal namoro entre mídia e tal partido seria interrompido, em 2005, com o escândalo político chamado Mensalão, quando a imagem do PT e do governo Lula passou a sofrer profundo desgaste na mídia (Azevedo, 2009; Biroli e Mantovani, 2014).

Em suma, a tradição dos estudos de mídia e política no Brasil, com o foco na análise das coberturas durante períodos eleitorais, tem mostrado viés consistente dos grandes órgãos de mídia contra o Partido dos Trabalhadores e os seus candidatos, eleição após eleição. O tópico da cobertura econômica, contudo, não foi sistematicamente explorado. Quando ele aparece, a referência é feita de maneira acessória na análise da cobertura política como um todo. Mesmo assim, o estudo da cobertura econômica se limita à metodologia da análise de enquadramento. Em outras palavras, nos contentamos em estudar a emissão e raramente tentamos conectá-la à recepção por parte da audiência/eleitores. Contudo, se a literatura do voto econômico está correta, então a cobertura da economia deveria receber mais atenção no estudo da interação entre mídia e política eleitoral, pois as pessoas obtêm a maior parte de suas informaçóes sobre a economia da mídia. Nas seções seguintes, pretendemos contribuir para cobrir essa deficiência, ao estimar a associaçáo entre o perfil da cobertura da economia consumida pelo leitor/espectador e o perfil do voto para a eleiçấo de 2014.

\section{Estudo da emissão}

Nesta seção do artigo, fazemos um estudo da emissão da notícia. Busca-se identificar quais enquadramentos foram dados pelos principais noticiários sobre o tema da economia, no período da campanha presidencial de 2014. A partir de evidências sobre o padrão de enquadramento dos meios, criamos hipóteses acerca do comportamento político dos públicos de cada um deles, no que diz respeito à avaliação do governo federal e da situação da economia.

Escolhemos para a análise os três principais jornais impressos do país em termos de tiragem: Folha de S. Paulo, O Estado de S. Paulo e O Globo; e o telejornal brasileiro de maior audiência, o Jornal $\mathrm{Na}$ cional. O período estudado compreende o intervalo entre 5 de agosto e 4 de novembro de 2014, abrangendo grande parte do período oficial da campanha presidencial de 2014 - aproximadamente $75 \%$ dele - e todo o período de propaganda eleitoral. ${ }^{2}$

Seguindo a tendência dos estudos sobre a cobertura jornalística, a partir das abordagens da agenda setting e do enquadramento, descrevemos a cobertura da economia mediante o volume de informaçáo (que está relacionado com a capacidade de agendar, pautar o assunto) e da valência das notícias (que diz respeito à interpretação e julgamento acerca dos eventos). O volume de informaçáo foi mensurado pelo número absoluto e pela porcentagem de matérias sobre economia publicadas e divulgadas no período delimitado. Na sequência, o objetivo foi identificar as valências positiva, neutra e negativa atribuídas pelos veículos nas matérias sobre economia. As matérias que receberam valência neutra foram descartadas da análise. A fim de continuar mapeando a interpretação e o julgamento que o veículo faz da economia, buscamos mensurar o quanto as matérias com valências negativa e positiva foram associadas às mençóes ao governo federal.

Os resultados mostram que o jornal que mais enfatiza o tema economia, em termos absolutos e proporcionais, é o O Estado de S. Paulo (22\%), seguido de $O$ Globo (19\%); na sequência, o Jornal Nacional (18\%) e a Folha de S. Paulo (17\%). Registra-se, contudo, que as taxas de presença das matérias são muito próximas nos veículos. Ou seja, a 
economia contou com aproximadamente $20 \%$ do espaço da cobertura total dos jornais.

Um levantamento de Arruda (1995), sobre a cobertura do Plano Real pelo Jornal Nacional, na disputa presidencial de 1994, apontava para aproximadamente $19 \%$ do tempo total do telejornal em todo o período, exceto na reta final da campanha, após o dia 20 de setembro, quando a cobertura cresceu para 25\%. O estudo de Conti (2015) sobre a cobertura do jornalismo político, entre os anos de 1995 e 2002, durante o mandato do presidente Fernando Henrique, quando o então presidente privatizou estatais, como a Vale do Rio Doce e a Telebrás, aponta que o espaço destinado às notícias de economia variou bastante nas capas das revistas Veja (21\%), Isto É (8\%), Carta Capital (38\%) e Época (15\%). De toda forma, podemos concluir que as taxas encontradas neste estudo refletem um comportamento padrão da cobertura da economia.

No que toca às valências, verificamos que a Folha de S. Paulo, embora seja o veículo que menos aborda o tema da economia, é aquele que mais evidencia os seus aspectos negativos, com $71 \%$ do total de notícias sobre o tema com esse viés. $\mathrm{Na}$ sequência decrescente de cobertura negativa aparecem $O$ Estado (68\%) e $O$ Globo (65\%). O JNé o segundo veículo de notícias que menos pauta a economia, entre os estudados por nós, bem como o jornal que menos adota valência negativa: $55 \%$ do total de notícias sobre o tema. Assim, o que se verifica até o momento é que, embora a Folha de S. Paulo seja o veículo que menos pauta a economia, quando o faz, ela apresenta uma interpretação mais negativa do tema. Por sua vez, o $J N$ - dentre os demais veículos, o que pauta menos o assunto economia - apresenta uma leitura menos negativa do que as de seus pares.

Tal resultado não seria previsível a partir de estudo de Aldé et al. (2007). Ao analisarem a cobertura dos três jornais impressos em 2006, ainda que não tenham se concentrado exclusivamente sobre a análise da economia, os autores não identificaram tendência maior na Folha de S. Paulo no que tange à adoção de validade negativa. Em sentido similar, Biroli e Mantovani (2014), ao estudarem a cobertura no mesmo jornal paulista, chegam à conclusão de que se trata de um jornal com mais abertura ao pluralismo do que os demais.
Por fim, sobre a associação do tipo de interpretação da economia à menção ao governo, verifica-se que $84 \%$ das matérias com valência negativa sobre a economia veiculadas no $J N$ são associadas ao governo federal. No outro extremo, dentre os informativos analisados, temos a Folha de S. Paulo, em cuja cobertura $42 \%$ dos textos com valência negativa sobre a economia são associados ao governo federal. Os jornais O Estado de S. Paulo e O Globo apresentam taxas de $63 \%$ e $55 \%$, respectivamente.

Em síntese, a Folha de S. Paulo é o jornal que menos pauta a economia, embora seja o que apresenta uma leitura mais negativa do assunto, bem como o meio que menos relaciona matérias econômicas de valência negativa ao Governo Federal. Por sua vez, o Jornal Nacional é aquele que, embora também paute menos o assunto, apresenta a leitura menos negativa da economia e o jornal que mais relaciona matérias negativas ao governo federal.

Os resultados aqui encontrados surpreendem em alguns aspectos. É de se esperar que um telejornal de TV aberta, com ampla audiência, como o é o Jornal Nacional, tenda a dedicar menos tempo à economia do que os jornais impressos, por se tratar de um tema mais complexo, que requer mais recursos cognitivos e mobilização do público para a sua compreensão (Carroll, 2003). Da mesma maneira, se espera que nestes veículos a interpretação e o julgamento do noticiário sejam mais explícitos. Nesse aspecto, vale salientar que o $J N$ dedicou mais espaço à economia do que a Folha de S. Paulo, contrariando a expectativa criada a partir da teoria. Contudo, reforçando os achados de Carroll (2003), o $J N$ foi aquele que vinculou ao governo federal a maior porcentagem de matérias com valência negativa e com valência positiva em relação a seus pares.

Considerando os resultados da análise de conteúdo aqui encontrados e as teorias de enquadramento da mídia e de voto econômico, podemos elaborar algumas hipóteses. Para a elaboração de hipóteses, assumimos que o enquadramento da cobertura jornalística pode estar relacionado à avaliação que o eleitor faz da economia e, consequentemente, à avaliaçâo do governo feita pelo eleitor. Isto quer dizer que, se determinado veículo noticioso oferecer enquadramento da economia com interpretação mais negativa do que os demais, pode-se esperar que 
Tabela 1

Análise de Conteúdo Sobre a Cobertura da Economia de O Estado de S. Paulo, O Globo, Folha de S. Paulo e Jornal Nacional.

\begin{tabular}{|c|c|c|c|c|}
\hline & \\
\hline & $\begin{array}{l}E S P \\
(824)\end{array}$ & $\begin{array}{l}\text { O Globo } \\
(687)\end{array}$ & $\begin{array}{l}\text { FSP } \\
(385)\end{array}$ & $\begin{array}{l}J N \\
(704)\end{array}$ \\
\hline \multirow[t]{2}{*}{ Porcentagem de matérias de economia no total de matérias } & $22 \%$ & $19 \%$ & $17 \%$ & $18 \%$ \\
\hline & 180 & 134 & 66 & 127 \\
\hline \multirow{2}{*}{ Porcentagem de matérias de economia com valência positiva } & $10 \%$ & $8 \%$ & $6 \%$ & $9 \%$ \\
\hline & 19 & 11 & 12 & 11 \\
\hline \multirow[t]{2}{*}{ Porcentagem de matérias de economia com valência negativa } & $68 \%$ & $65 \%$ & $71 \%$ & $55 \%$ \\
\hline & 123 & 87 & 47 & 70 \\
\hline \multirow{2}{*}{$\begin{array}{l}\text { Porcentagem de matérias de economia com valência negativa que } \\
\text { estiveram relacionadas ao governo federal }\end{array}$} & $43.3 \%$ & $35.82 \%$ & $30.3 \%$ & $46.45 \%$ \\
\hline & 78 & 48 & 20 & 59 \\
\hline \multirow{2}{*}{$\begin{array}{l}\text { Porcentagem de matérias de economia com valência positiva que } \\
\text { estiveram relacionadas ao governo federal }\end{array}$} & $3.3 \%$ & $2.2 \%$ & $0 \%$ & $6 \%$ \\
\hline & 6 & 3 & 0 & 8 \\
\hline \multirow[t]{2}{*}{ Saldo dos resultados das duas últimas linhas } & $40 \%$ & $33.6 \%$ & $30.3 \%$ & $40.4 \%$ \\
\hline & 72 & 45 & 20 & 51 \\
\hline
\end{tabular}

Fonte: Base de dados Manchetômetro/Laboratório de Estudos da Mídia e Esfera Pública (Lemep).

o seu público tenda a manifestar uma avaliação mais negativa da economia do que os demais.

Da mesma forma, acreditamos que se determinado veículo noticioso associar de maneira mais recorrente notícias econômicas com valência negativa, ao governo federal, pode-se esperar que o seu público tenda a ter uma avaliação mais negativa do governo do que os leitores/audiência dos demais veículos.

Para o teste das hipóteses, nos baseamos nos públicos da Folha de S. Paulo, do O Globo e o do Jornal Nacional. Como já dissemos, a Folha de $S$. Paulo é o jornal que apresenta o enquadramento do noticiário econômico com mais valência negativa dentre os analisados. O Jornal Nacional, por sua vez, é o noticioso que apresenta o enquadramento da economia com valência menos negativa dentre os veículos analisados. Já $O$ Globo apresenta um enquadramento intermediário. A nossa hipótese é de que a audiência de um veículo que imprime e enquadra uma realidade econômica negativa em seu noticiário tende a estar associada a um comportamento de avaliação mais negativa da economia. Dessa forma, esperamos que tanto os leitores da $\mathrm{Fo}_{\text {- }}$
Lha e de $O$ Globo quanto a audiência do $J N$ tendam a uma avaliação mais negativa da economia do que as pessoas que não fazem parte destes públicos. Espera-se, ainda, que o efeito redutor no modelo estatístico seja mais expressivo no caso do público da Folha do que nos casos do público de $O$ Globo e da audiência do $J N$, em relação a sua "não audiência".

Sobre a avaliação do desempenho do governo federal, a Folha de S. Paulo é o veículo que menos associa notícias econômicas negativas a ele. Por sua vez, o Jornal Nacional é aquele que apresenta a mais forte associação entre avaliação negativa da economia e mençóes ao governo federal. Mais uma vez, o jornal $O$ Globo apresentou enquadramento intermediário. A nossa hipótese é de que o público de um veículo que imprime e enquadra uma realidade econômica negativa associada ao governo federal tende a ter uma avaliação mais negativa do governo federal. Dessa forma, esperamos que tanto os leitores da FSP e do $O$ Globo quanto a audiência do $J N$ tendam a uma avaliação mais negativa do governo federal em relação aos seus não públicos. Espera-se ainda que o efeito redutor no modelo estatístico seja mais expres- 
Tabela 2

Avaliação do Governo e da Economia, 2014 (\%)

\begin{tabular}{lll}
\hline Avaliaçáo & Desempenho do Governo & Situação da Economia Nacional \\
\hline Negativa & 21,9 & 25,7 \\
\hline Neutra & 43,5 & 43,5 \\
\hline Positiva & 34,6 & 34,6 \\
\hline
\end{tabular}

Fonte: Pesquisa Brasileira de Mídia, 2015.

sivo no caso da audiência do $J N$ do que nos casos dos públicos dos dois jornais impressos.

\section{Estudo da recepçáo: Pesquisa de opinião com os públicos dos noticiosos}

Nosso objetivo, nesta seção do texto, é identificar se há diferença de atitudes políticas, referentes especificamente à avaliação do governo federal e à avaliação da economia, entre os leitores e os não leitores dos jornais Folha de São Paulo, O Globo e entre a audiência e a não audiência do Jornal Nacional.

É importante esclarecer que estamos nos referindo sempre a associaçóes e relaçóes entre a cobertura midiática e as avaliaçóes, não avançando na afirmação de causalidades. Como nos valemos de dados observacionais de opinião pública e registro de coberturas, de fato, não podemos garantir que os eleitores que originalmente avaliam negativamente a economia e o governo não procurem os veículos de comunicação com as coberturas mais negativas. Dessa forma, com os dados de que dispomos, não podemos testar a hipótese causal inversa. Trata-se, portanto, de uma limitação que assumimos e que nos obriga a tratar nossos achados como evidências de relacionamentos, ainda que empreguemos modelos multivariados de regressão. $\mathrm{Na}$ exposição dos resultados, ao nos referirmos a efeitos ou impactos, termos normalmente utilizados em análise multivariada, não nos reportamos às capacidades preditivas das variáveis, mas a intensidades de associaçóes e relacionamentos controlados pela presença de medidas sociodemográficas relevantes.

O banco de dados utilizado nesta fase do artigo advém da "Pesquisa Brasileira de Mídia, de 2015", um survey quantitativo nacional encomendado pela Secretaria de Comunicação da Presidência da República, realizada pelo Ibope entre os dias 5 e 22 de novembro de 2014, mediante entrevistas domiciliares pessoais. $\mathrm{O}$ questionário com 85 perguntas foi respondido por 18.312 pessoas maiores de 16 anos distribuídas em 848 municípios brasileiros. $\mathrm{O}$ desenho amostral da pesquisa permite não apenas representatividade nacional, mas também a desagregação dos dados pelos 26 estados da federação e o Distrito Federal.

Estimamos os modelos de regressão logística multinominal, nos quais as variáveis dependentes foram a avaliação do governo federal e a avaliação retrospectiva sociotrópica da economia. Para ambas as variáveis foram adotados três valores: "negativa", "neutra" e "positiva". A categoria "negativa" nos dois casos foi utilizada como referência. Os dados descritivos referentes às variáveis dependentes estão na Tabela 2.

Como variável explicativa central foi utilizado o uso de mídias específicas (Jornal Nacional, $O$ Globo e Folha de S. Paulo). As análises apresentadas nesta seção consideram os dados de consumo dos jornais impressos e do Jornal Nacional aos finais de semana, e, como controles sociodemográficos, os dados relativos ao sexo, idade, escolaridade, classe social (Critério Econômico Brasil ${ }^{3}$ ) e região de moradia dos entrevistados. Com essas inclusóes pretendemos verificar a consistência dos relacionamentos e afastar possíveis conclusôes espúrias.

Optamos por utilizar os dados da pergunta sobre a leitura no "final de semana", pois os percentuais para a leitura "de segunda a sexta" são muito baixos para as análises de regressão. Dado o baixíssimo 
Tabela 3

Uso de Mídias Específicas, Brasil, Sáo Paulo e Rio de Janeiro (\%)

\begin{tabular}{llll}
\hline Mídia & Brasil & SP & RJ \\
\hline Jornal Nacional & 30,5 & - & - \\
\hline O Globo & 7 & - & 5,36 \\
\hline Folha de S. Paulo & 7 & 2,5 & - \\
\hline O Estado de S. Paulo &, 4 & 1,4 & - \\
\hline
\end{tabular}

Fonte: Pesquisa Brasileira de Mídia, 2015.

número de casos de leitores dos grandes jornais na amostra, optou-se por analisar apenas os dois jornais impressos com leitorado mais expressivo, a Folha de $S$. Paulo e $O$ Globo, que é sediado no Rio de Janeiro. Ainda com o objetivo de aumentar o percentual de público dos jornais impressos, optamos por trabalhar com amostras estaduais para as análises dos leitores dos jornais impressos, uma vez que, a despeito destes jornais terem pretensóes nacionais, há um forte enraizamento estadual na sua cobertura, bem como no perfil de público e de anunciantes.

\section{A recepção do Jornal Nacional}

A Tabela 4 apresenta dois modelos, um para a avaliação econômica e outro para a avaliação do governo. No primeiro, nossa principal variável explicativa não se mostrou estatisticamente relevante (ao nível de 0,05) em nenhum dos contrastes de categorias de avaliação, indicando que não há qualquer associação estatística entre a condição de audiência desse telejornal e as avaliaçóes positivas ou negativas acerca do governo.

Em relação às variáveis de controle, todavia, o quadro é bastante diverso, já que apenas o sexo dos entrevistados deixou de alcançar o nível exigido de significância. Quanto mais se avança na idade menor a tendência de avaliar de forma neutra e positiva o governo federal. O mesmo se dá com a escolaridade: quanto maior for o nível escolar, menor o apoio ao governo. A classe social apresenta efeito positivo de cerca de $10 \%$ sobre a chance de manifestar a avaliação neutra e a avaliação positiva. Mo- rar nas regióes Norte e Nordeste aumenta as chances de avaliar o desempenho do governo federal de forma neutra - em $40 \%$ e $23 \%$, respectivamente e positiva - em $122 \%$ e $107 \%$, respectivamente, tomando por referência a região Sudeste. Morar no Sul aumenta as chances de avaliar o desempenho do governo federal de forma positiva em $45 \%$. Todavia, a situaçấo de morar no Centro-Oeste reduz as chances de avaliar o desempenho do Governo Federal de forma neutra - em $24 \%$ - e positiva em $16 \%$-, sempre tomando como elemento de comparação a região Sudeste.

No segundo modelo, a variável relativa à audiência se mostrou estatisticamente significativa apenas para a categoria positiva, com efeito redutor de $18,3 \%$, ou seja, o grupo de pessoas que assistem ao telejornal tem $18,3 \%$ menos chance de avaliar positivamente a situação da economia nacional. Assim como no modelo anterior, é importante destacar que esse efeito já é controlado por todas as variáveis sociodemográficas inseridas na equação, mesmo que mantidas estáveis as idades, escolaridade, classe social, sexo e local de moradia, o efeito da audiência continua estatisticamente válido.

Tratando desses controles, os efeitos foram bem distintos entre as categorias neutra e positiva. $\mathrm{Na}$ categoria de avaliação neutra, escolaridade, classe social e região de moradia se mostraram relevantes. A escolaridade apresenta efeito negativo de $2,6 \%$ sobre a chance de manifestar esse tipo de avaliação. A classe social apresenta efeito positivo de $5 \%$ sobre a chance de manifestar avaliação neutra. Os efeitos das regióes são positivos no Norte e Nordeste e negativo 
Tabela 4

Efeitos da Audiência do Jornal Nacional sobre a Avaliaçáo do Governo e a Situação da Economia Nacional, 2014

\begin{tabular}{|c|c|c|c|c|}
\hline & \multicolumn{2}{|c|}{ Desempenho do Governo } & \multicolumn{2}{|c|}{ Situaçáo da Economia Nacional } \\
\hline & $\begin{array}{l}\text { Neutra } \\
\operatorname{Exp}(b)\end{array}$ & $\begin{array}{l}\text { Positiva } \\
\operatorname{Exp}(b)\end{array}$ & $\begin{array}{l}\text { Neutra } \\
\operatorname{Exp}(b)\end{array}$ & $\begin{array}{l}\text { Positiva } \\
\operatorname{Exp}(b)\end{array}$ \\
\hline Audiência do Jornal Nacional & $\begin{array}{l}1,018 \\
(, 044)\end{array}$ & $\begin{array}{l}1,001 \\
(, 046)\end{array}$ & $\begin{array}{l}990 \\
(, 042)\end{array}$ & $\begin{array}{l}, 817^{* * *} \\
(, 044)\end{array}$ \\
\hline Idade & $\begin{array}{l}1,001 \\
(, 001)\end{array}$ & $\begin{array}{l}1,005^{* * *} \\
(, 001)\end{array}$ & $\begin{array}{l}1,001 \\
(, 001)\end{array}$ & $\begin{array}{l}1,002 \\
(, 001)\end{array}$ \\
\hline Escolaridade & $\begin{array}{l}988 \\
(, 012)\end{array}$ & $\begin{array}{l}, 925^{* * *} \\
(, 012)\end{array}$ & $\begin{array}{l}, 974^{*} \\
(, 011)\end{array}$ & $\begin{array}{l}, 915^{* * *} \\
(, 011)\end{array}$ \\
\hline Classe Social (Critério Brasil) & $\begin{array}{l}1,109^{* * *} \\
(, 020)\end{array}$ & $\begin{array}{l}1,105^{* * *} \\
(, 021)\end{array}$ & $\begin{array}{l}1,052^{* *} \\
(, 020)\end{array}$ & $\begin{array}{l}1,112 \\
(, 020)\end{array}$ \\
\hline Sexo (Feminino) & $\begin{array}{l}1,013 \\
(, 041)\end{array}$ & $\begin{array}{l}1,007 \\
(, 042)\end{array}$ & $\begin{array}{l}, 964 \\
(, 039)\end{array}$ & $\begin{array}{l}, 922^{*} \\
(, 041)\end{array}$ \\
\hline Região Norte & $\begin{array}{l}1,395^{* * *} \\
(, 063)\end{array}$ & $\begin{array}{l}2,220^{* * *} \\
(, 066)\end{array}$ & $\begin{array}{l}1,268^{* * *} \\
(, 061)\end{array}$ & $\begin{array}{l}1,993^{* * *} \\
(, 062)\end{array}$ \\
\hline Região Nordeste & $\begin{array}{l}1,225^{* * *} \\
(, 058)\end{array}$ & $\begin{array}{l}2,070^{* * *} \\
(, 060)\end{array}$ & $\begin{array}{l}1,110 \mathrm{a} \\
(, 055)\end{array}$ & $\begin{array}{l}1,519^{* * *} \\
(, 057)\end{array}$ \\
\hline Região Sul & $\begin{array}{l}1,018 \\
(, 068)\end{array}$ & $\begin{array}{l}1,448^{* * *} \\
(, 072)\end{array}$ & $\begin{array}{l}991 \\
(, 065)\end{array}$ & $\begin{array}{l}1,124 \\
(, 069)\end{array}$ \\
\hline Região Centro-Oeste & $\begin{array}{l}, 759^{* *} \\
(, 065)\end{array}$ & $\begin{array}{l}, 837^{*} \\
(, 071)\end{array}$ & $\begin{array}{l}, 824^{* *} \\
(, 063)\end{array}$ & $\begin{array}{l}, 600^{* * *} \\
(, 072)\end{array}$ \\
\hline AIC & 36443.82 & & 37264.15 & \\
\hline Convergência residual & 36393.82 & & 37224.15 & \\
\hline
\end{tabular}

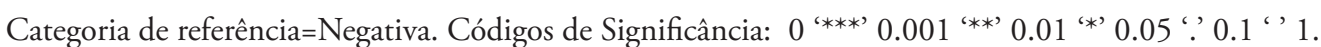

Fonte: Pesquisa Brasileira de Mídia, 2015.

no Centro-Oeste, em relação ao Sudeste. E, no caso da região Sul, não há qualquer efeito. $\mathrm{Na}$ categoria de avaliação positiva, escolaridade e sexo feminino apresentam efeitos negativos e bastante próximos. Os mais escolarizados, portanto, têm menos chances de avaliar positivamente a economia nacional, assim como as mulheres. $\mathrm{O}$ efeito das regióes aponta para avaliaçóes mais positivas no Norte e Nordeste e negativas no Centro-Oeste. Mais uma vez, sem efeito para o caso da região Sul.
Recepção dos leitores de jornais - a Folha de S. Paulo $e$ O Globo.

A Tabela 5 apresenta as estimativas geradas pelos modelos que tomam como principal variável independente a condição de leitor do jornal A Folha de S. Paulo entre os paulistas. Tanto sobre a avaliação do governo quanto sobre a avaliação da economia, constatamos que ser leitor do jornal impresso, ao menos nos finais de semana, não é uma 
Tabela 5

Efeitos da Leitura da Folha de S. Paulo sobre a Avaliaçáo do Governo e na Situaçáo da Economia Nacional, 2014

\begin{tabular}{lllll} 
& \multicolumn{2}{l}{ Desempenho do Governo } & \multicolumn{2}{l}{ Situaçáo da Economia Nacional } \\
\cline { 2 - 5 } & $\begin{array}{l}\text { Neutra } \\
\text { Exp(b) }\end{array}$ & $\begin{array}{l}\text { Positiva } \\
\mathbf{E x p}(\mathbf{b})\end{array}$ & $\begin{array}{l}\text { Neutra } \\
\mathbf{E x p}(\mathbf{b})\end{array}$ & $\begin{array}{l}\text { Positiva } \\
\mathbf{E x p}(\mathbf{b})\end{array}$ \\
\hline Folha de S. Paulo &, 790 &, 804 &, 760 &, 631 \\
& $(, 335)$ & $(, 423)$ & $(, 329)$ & $(, 431)$ \\
\hline Idade &, 998 &, 995 &, 998 &, 993 \\
& $(, 004)$ & $(, 005)$ & $(, 004)$ & $(, 004)$ \\
\hline Escolaridade &, 937 a &, $934 a$ &, 960 &, 943 \\
& $(, 034)$ & $(, 041)$ & $(, 033)$ & $(, 039)$ \\
\hline Classe Social (Critério Brasil) & 1,021 & 1,077 & 1,021 & 1,039 \\
& $(, 057)$ & $(, 068)$ & $(, 020)$ & $(, 020)$ \\
\hline Sexo (Feminino) &, 933 &, 997 &, 913 &, 873 \\
& $(, 109)$ & $(, 129)$ & $(, 039)$ & $(, 041)$ \\
\hline AIC & 3808.027 & & 3905.943 & \\
\hline Convergência residual & 3784.027 & & 3881.943 & \\
\hline
\end{tabular}

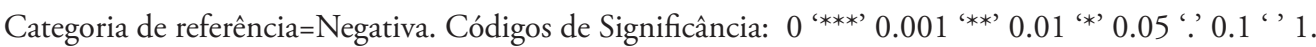

Fonte: Pesquisa Brasileira de Mídia, 2015.

condição estatisticamente relevante para a adesão a avaliaçóes positivas ou negativas acerca do governo ou da economia. Da mesma forma, não se verificou efeito das variáveis de controle na avaliação do desempenho do governo federal e nem mesmo na avaliação da economia entre as categorias neutra e positiva. A exceção ficou apenas por conta da escolaridade, que reduz a chance de avaliaçóes neutras e positivas do governo.

A Tabela 6 apresenta as estimativas geradas pelos modelos que tomam como principal variável independente a condição de leitor do jornal $O$ Globo entre os fluminenses. Sobre a avaliação do governo, constatamos que ser leitor do jornal impresso ao menos no fim de semana não é uma condição estatisticamente relevante em qualquer dos contrastes de categorias, indicando que não há qualquer associação estatística entre a condição de leitor desse jornal no estado de Rio de Ja- neiro e avaliaçóes positivas, neutras ou negativas acerca do governo.

Em relação às variáveis de controle, apenas escolaridade e idade dos entrevistados alcançaram o nível exigido de significância. Sobre a avaliação neutra, quanto mais cresce a escolaridade mais reduz a chance de avaliar desse modo o governo. Já quanto mais se avança na idade maior a tendência de avaliar de forma positiva o governo federal.

No segundo modelo, a variável relativa à leitura de $O$ Globo se mostrou estatisticamente significativa apenas para a categoria positiva, com efeito redutor de $61 \%$, ou seja, o grupo de pessoas que lê o jornal tem $61 \%$ menos chance de avaliar positivamente a situação da economia nacional. Assim como no modelo anterior, é importante destacar que esse efeito já é controlado por todas as variáveis sociodemográficas inseridas na equação, as quais não alcançaram o nível exigido de significância. 


\section{Tabela 6}

Efeitos da Leitura de $O$ Globo sobre a Avaliaçáo do Governo e na Situaçáo da Economia Nacional, 2014

\begin{tabular}{lllll} 
& \multicolumn{2}{l}{ Desempenho do Governo } & \multicolumn{2}{l}{ Situaçáo da Economia Nacional } \\
\cline { 2 - 5 } & $\begin{array}{l}\text { Neutra } \\
\text { Exp(b) }\end{array}$ & $\begin{array}{l}\text { Positiva } \\
\mathbf{E x p}(\mathbf{b})\end{array}$ & $\begin{array}{l}\text { Neutra } \\
\mathbf{E x p}(\mathbf{b})\end{array}$ & $\begin{array}{l}\text { Positiva } \\
\mathbf{E x p}(\mathbf{b})\end{array}$ \\
\hline O Globo & 1,018 &, 936 &, 570 &, $391^{*}$ \\
& $(, 416)$ & $(, 462)$ & $(, 362)$ & $1,456)$ \\
\hline Idade & 1,006 & $1,014^{*}$ & 1,007 & $(, 015$ \\
& $(, 006)$ & $(, 006)$ & $(, 005)$ &, 980 \\
\hline Escolaridade &, $885^{*}$ &, 911 &, 929 & $(, 060)$ \\
\hline Classe Social (Critério Brasil) & $(, 058)$ & $(, 063)$ & $(, 053)$ &, 925 \\
&, 911 &, 899 &, 880 & $(, 103)$ \\
\hline Sexo (Feminino) & $(, 098)$ & $(, 109)$ & $(, 091)$ &, 691 \\
&, 823 &, 952 &, 799 & $(, 195)$ \\
\hline AIC & $(, 182)$ & $(, 202)$ & $(, 172)$ & \\
\hline Convergência residual & 1676.185 & & 1721.988 & \\
\hline
\end{tabular}

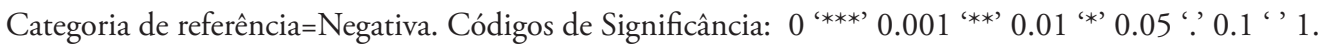

Fonte: Pesquisa Brasileira de Mídia, 2015.

\section{Discussão}

Inicialmente, tomamos o argumento segundo o qual o jornalismo informa o eleitor, capacitando-o para o discernimento acerca da economia (Soroka et al., 2015). Avançamos tal discussão adotando o princípio de acordo com o qual o enquadramento da cobertura jornalística pode interferir na avaliação que o eleitor faz da economia e do governo (De Boef e Kellstedt, 2004; Duch e Stevenson, 2008). Isto quer dizer que, se determinado noticioso oferecer enquadramento da economia com uma interpretação mais negativa do que os demais veículos, pode-se esperar que o seu público tenda a ter uma avaliação mais negativa da economia em comparaçâo com os leitores/audiência dos outros veículos. Os resultados aqui encontrados confirmam apenas parcialmente esses pressupostos.

Como foi verificado, a Folha de S. Paulo foi o jornal que apresentou enquadramento do noticiário econômico com mais valência negativa dentre os analisados. O jornal $O$ Globo adotou uma postura intermediária. O Jornal Nacional, por sua vez, foi o noticioso que apresentou o enquadramento da economia com valência menos negativa, dentre os analisados. A nossa hipótese era de que a audiência de um veículo que imprime e enquadra uma realidade econômica negativa em seu noticiário tende a estar associada a um comportamento de avaliação mais negativa da economia. Dessa forma, esperávamos que tanto os leitores de Folha e $O$ Globo quanto a audiência do $J N$ tendessem a uma avaliação mais negativa da economia em relaçáo aos públicos dos demais veículos. Esperávamos ainda que o efeito redutor no modelo estatístico fosse mais expressivo no caso do público da Folha de S. Paulo em comparação com o seu não público do que no caso do $O$ Globo e da audiência do $J N$ em relação a sua não audiência.

Tais expectativas não foram totalmente confirmadas. Não foi possível identificar qualquer tipo de 
impacto estatisticamente significante entre ser leitor ou não da Folha de S. Paulo e a avaliação da economia. Todavia, o grupo de pessoas leitoras de $O$ Globo demonstrou ter $54,4 \%$ menos chance de avaliar positivamente a situação da economia nacional do que os demais entrevistados no estado do Rio de Janeiro. Do mesmo modo, o grupo de pessoas que assiste ao telejornal $J N$ mostrou ter 18,3\% menos chance de avaliar positivamente a situação da economia nacional do que os demais entrevistados.

A Folha de S. Paulo foi o veículo que menos associou notícias econômicas negativas com o governo federal. Por sua vez, $O$ Globo adotou uma postura intermediária. Já o Jornal Nacional foi aquele que apresentou a associação mais forte entre avaliação negativa da economia e mençôes ao governo federal. A nossa hipótese era de que o público de um veículo que imprime e enquadra uma realidade econômica negativa associada ao governo federal em seu noticiário tendesse a estar associado a um comportamento de avaliação mais negativa do governo. No entanto, verificou-se que ler qualquer um dos dois jornais ou não e assistir ou não o telejornal da Globo não tem impacto diferencial na avaliação que o eleitor faz do governo federal. Nesse caso, a nossa hipótese não é confirmada.

Certamente tal falta de diferença entre o consumo ou não de determinadas mídias não cancela a hipótese de que o efeito dos agendamentos e enquadramentos da grande imprensa na formação da opiniāo pública seja tão amplo que atinja toda a sociedade, isto é, mesmo aqueles que não consomem diretamente os principais veículos. Mas tal hipótese teria que ser testada por um desenho de pesquisa diferente daquele apresentado aqui.

Para os estudiosos do voto econômico, este artigo pretende ter demonstrado a forte associação entre ser público do $O$ Globo e do $J N$ e a avaliação retrospectiva sociotrópica da economia na disputa presidencial de 2014, uma vez controladas as variáveis sociodemográficas. Para os estudiosos da emissão da notícia, demonstramos não somente que a cobertura da economia no pleito presidencial de 2014 imprimiu uma agenda mais negativa tanto no JN quanto nos quality newspapers, mas também que houve correspondência entre o viés da cobertura e o comportamento do público.
Ainda que a metodologia adotada aqui não possibilite o estabelecimento de relaçóes causais, ou seja, determinar se as mídias formam a opinião do público ou se o público com determinado perfil de opinião procura as mídias mais próximas das opinióes dele, é prudente e razoável supor que os dois efeitos coexistam em nossas sociedades. Para avançarmos mais na compreensão desse fenômeno social, táo crucial para o funcionamento das democracias representativas contemporâneas, é necessária a utilização de ferramentas quantitativas especialmente dedicadas ao tema e de pesquisas qualitativas que possam gerar subsídios para a compreensão do complexo processo de recepção.

\section{Notas}

1 Um quality paper ou quality newspaper é definido da seguinte maneira pelo Oxford English Dictionary: "A newspaper, typically a broadsheet, that is considered to deal seriously with issues and to have high editorial standards". Esse conceito, também às vezes referido coletivamente como quality press, surgiu no Reino Unido para diferenciar a imprensa "séria" dos tabloides sensacionalistas.

2 O início oficial da campanha foi 6 de julho. Em 19 de agosto, o início da propaganda eleitoral gratuita no rádio e televisão. Em 5 de outubro, foi o primeiro turno das eleiçóes e,em 28 de outubro, o segundo turno das eleições.

3 O Critério Brasil é um estimador padronizado da capacidade de consumo dos domićlios produzido pela Associação Brasileira de Empresas de Pesquisa, a partir da posse de bens, acesso a serviços públicos e a escolaridade dos indivíduos. Disponível em http://www. abep.org/criterio-brasil.

\section{BIBLIOGRAFIA}

ALBUQUERQUE, Afonso de. (2013), “Em nome do público: jornalismo e política nas entrevistas dos presidenciáveis ao Jornal Nacional”. Revista da Associação Nacional dos Programas de Pós-Graduação em Comunicação, E-compos, 16 (2): 1-23.

ALDÉ, Alessandra. (2003), "As eleições presidenciais de 2002 nos jornais". ALCEU 3, 6: 93-121. 
ALDÉ, Alessandra; MENDES, Gabriel \& FIGUEIREDO, Marcus. (2007), "Tomando partido: imprensa e eleiçóes presidenciais em 2006". Politica e Sociedade, 10: 153-172.

ALESINA, Alberto; LONDREGAN, John \& ROSENTHAL, Howard. (1993), "A model of the political economy of the United States". The American Political Science Review, 87 (1): 12-33.

AMARAL, Oswaldo E. do \& RIBEIRO, Pedro Floriano. (2015), "Por que Dilma de novo? Uma análise exploratória do Estudo Eleitoral Brasileiro de 2014". Revista de Sociologia e Politica, 23: 107-123.

ANDERSON, Christopher. (2008), "The Interaction of structures and voter behavior", in Russell Dalton e Hans-Dieter Klingemann (orgs.), The Oxford Handbook of Political Behavior, Oxford University Press, pp. 589-610.

ARRUDA, Lilian Rose. (1995). O vôo das notícias: O Jornal Nacional e as Eleiçóes de 94. Pontifícia Universidade Católica de São Paulo, São Paulo. AZEVEDO, Fernando. (2000), "Imprensa, campanha presidencial e agenda da mídia", in Antonio Albino Canelas Rubim (org.), Midia e eleiçóes de 98, João Pessoa, Salvador, Editora da UFPB, Ediçóes Facom.

AZEVEDO, Fernando. (2009), "A imprensa brasileira e o PT: um balanço das coberturas presidenciais (1989 a 2006)". Revista Eco-Pós, 12 (3): 48-65.

BIROLI, Flávia e MANTOVANI, Denise. (2014), "A parte que me cabe nesse julgamento: a Fotha de S. Paulo na cobertura ao processo do "mensalão". Opinião Pública, 20 (2): 204-218.

BLOOD, Deborah J. e PHILliPS, Peter C. B. (1995), "Recession headline news, consumer sentiment, the state of the economy and presidential popularity: a time series analysis 19891993”. International Journal of Public Opinion Research, 7 (1): 2-22.

BRUG, Wouter van der; EIJK, C. van der \& FRANKLIN, Mark N. (2007), The economy and the vote: economic conditions and elections in fifteen countries, Nova York, Cambridge University Press.

CARREIRÃO, Yan de Souza. (2002), A decisão do voto nas eleiçóes presidenciais brasileiras, Floria-
nópolis/Rio de Janeiro, Editora da UFSC/Editora FGV.

COLLING, Leandro. (2004), "Os estudos sobre o Jornal Nacional nas eleições pós-ditadura e algumas reflexóes sobre o papel desempenhado em 2002, in Antonio Rubim e Albino Canelas (orgs.), Eleiçóes presidenciais em 2002: ensaios sobre mídia, cultura e política, São Paulo, Hacker Editores, pp. 53-67.

COLLING, Leandro. (2006). Os estudos sobre midia e eleiçóes presidenciais no Brasil pós-ditadura, UFBA, Salvador.

CONTIN, Ailton Alex. (2015), Midia e economia: limites, fatos e versóes, Unicamp, Campinas.

DE BOEF, Suzanna e KELLSTEDT, Paul M. (2004), "The political (and economic) origins of consumer confidence". American Journal of Political Science, 48 (4): 633-649.

DOWNS, Anthony. (1957), An economic theory of democracy. Nova York, Harper.

DUCH, Raymond M. (2007), "Comparative studies of the economy and the vote", in Carles Boix e Susan Carol Stokes (orgs.), The Oxford handbook of comparative politics, Oxford/New York, Oxford University Press, pp. 805-844.

DUCH, Raymond M., PALMER, Harvey D. \& ANDERSON, Christopher J. (2000), "Heterogeneity in perceptions of national economic conditions". American Journal of Political Science, 44 (4): 635-652.

DUCH, Raymond M. \& STEVENSON, Randolph T. (2008), The economic vote: how political and economic institutions condition election results. Nova York, Cambridge University Press.

ENTMAN, Robert M. (1993), "Framing: toward clarification of a fractured paradigm". Journal of Communication, 43 (4): 51-58.

ERIKSON, Robert S. (1990), "Economic conditions and the congressional vote: a review of the macrolevel evidence". American Journal of Political Science, 34 (2): 373-399.

ERIKSON, Robert S., MACKUEN, Michael \& STIMSON, James A. (2001), The macro polity. Nova York, Cambridge University Press.

FAIR, Ray C. (1978), "The effect of economic events on votes for president". The Review of Economics and Statistics, 60 (2): 159-173. 
FEREJOHN, John. (1986), "Incumbent performance and electoral control". Public Choice, 50 (1): 5-25.

FIORINA, Morris P. (1981), Retrospective voting in American national elections. New Haven, Yale University Press.

GITLIN, Todd. (2003), The whole world is watching : mass media in the making o unmaking of the New Left. Berkeley, CA, University of California Press.

GOIDEL, Robert K. \& LANGLEY, Ronald E. (1995), "Media coverage of the economy and aggregate economic evaluations: uncovering evidence of indirect media effects". Political Research Quarterly, 48 (2): 313-328.

GOODHART, C. A. E. \& BHANSALI, R. J. (1970), "Political economy". Political Studies, 18 (1): 43-106.

HABERMAS, Jurgen. (1996), Between facts and norms: contributions to a discourse theory of law and democracy, Cambridge, MIT Press.

HALLER, H. Brandon \& NORPOTH, Helmut. (1997), "Reality bites: news exposure and economic opinion”. Public Opinion Quarterly, 61 (4): 555-575.

HETHERINGTON, Marc J. (1996), "The Media's role in forming voters' national economic evaluations in 1992". American Journal of Political Science, 40 (2): 372-395.

HUNTER, Wendy e POWER, Timothy J. (2007), "Rewarding Lula: Executive Power, social policy, and the Brazilian elections of 2006". Latin American Politics and Society, 49 (1): 1-30.

IYENGAR, Shanto e KINDER, Donald R. (1987), News that matters : television and American opinion. Chicago, University of Chicago Press.

JACOBSEN, Kjeld. (2007), "A cobertura da mídia impressa aos candidatos nas eleiçóes de 2006, in Venício A. de Lima (org.), A mídia nas eleições de 2006, São Paulo, Editora Perseu Abramo, pp. 31-64.

KAREL-JAN, Alsem; STEVEN, Brakman; LEX, Hoogduin \& GERARD, Kuper. (2004). The impact of newspapers on consumer confidence: does spin bias exist? CESifo, Working papers n. 1328.

KRAMER, Gerald H. (1971), "Short-term fluctuations in U.S. voting behavior, 1896-1964”.
American Political Science Review, 65 (1): 131143.

KUCINSKI, Bernardo. (1998), A sindrome da antena parabólica: ética no jornalismo brasileiro. São Paulo, Fundação Perseu Abramo.

LAFAY, J.-D. . (1977), "Les conséquences électorales de la conjoncture économique: essaie de prévision chiffrée pour Mars 1978”. Vie et Sciences Économiques, 75: 1-7.

LANOUE, David J. (1987), "Economic prosperity and presidential popularity: sorting out the effects”. Political Research Quarterly, 40 (2): 237-245.

LARCINESE, Valentino; PUGLISI, Riccardo \& SNYDER JR, James M. (2011), "Partisan bias in economic news: evidence on the agenda-setting behavior of U.S. newspapers". Journal of Public Economics, 95 (9-10): 1178-1189.

LAU, Richard R. \& REDLAWSK, David P. (1997), "Voting Correctly". The American Political Science Review, 91 (3): 585-598.

LEWIS-BECK, Michael \& STEGMAIER, Mary. (2008), "Economic models of voting", in Russell Dalton e Hans-Dieter Klingemann (orgs.), The Oxford Handbook of Political Behavior, Oxford University Press, pp. 518-537.

LEWIS-BECK, Michael S. (1980), "Economic conditions and executive popularity: the French experience". American Journal of Political Science, 24 (2): 306-323.

LIMA, Venício \& GUAZINA, Liziane. (2004). "'Responsabilidade social' em tempos de crise: novo oficialismo do Jornal Nacional?”. Trabalho apresentado no XXVIII Encontro Anual da Anpocs.

LINS DA SILVA, Carlos Eduardo. (1990), "Indústria da comunicação: personagem principal das eleições presidenciais de 1989". Intercom - Revista Brasileira de Ciências da Comunicação, 13 (62-63): 121-127.

MARRA, Robin F. \& OSTROM, Charles W. (1989), "Explaining seat change in the U.S. House of Representatives, 1950-86". American Journal of Political Science, 33 (3): 541-569.

MENDES, Antonio Manuel Teixeira \& VENTURI, Gustavo. (2015), "Eleição presidencial: o Plano Real na sucessão de Itamar Franco". Opiniāo Pública, 2 (2): 14. 
MENDONÇA, Ricardo Fabrino \& SIMÓES, Paula Guimarães. (2012), "Enquadramento: diferentes operacionalizaçóes analíticas de um conceito”. Revista Brasileira de Ciências Sociais, 27 (79): 187-201.

MENEGUELLO, Rachel. (1994), "Electoral behavior in Brazil: the 1994 presidential elections". Social Science Journal, 146: 627-641.

MIGUEL, Luis Felipe. (1999a), "Mídia e eleiçôes: a campanha de 1998 na Rede Globo". Dados, 42 (2): 253-276.

MIGUEL, Luis Felipe. (1999b), "Mídia e manipulação política no Brasil: a Rede Globo e as eleiçóes presidenciais de 1989 a 1998". Comunicação e Política, 2/3: 119-138.

MIGUEL, Luis Felipe. (2004), "A descoberta da política: a campanha de 2002 na Rede Globo, in Hacker Editores (orgs.), Eleiçóes presidenciais em 2002: ensaios sobre midia, cultura e politica, São Paulo, Hacker Editores, pp. 95-105.

NADEAU, Richard, NIEMI, Richard G., DAVID, P. Fan \& AMATO, Timothy. (1999), "Elite economic forecasts, economic news, mass economic judgments, and presidential approval". The Journal of Politics, 61 (1): 109-135.

NICOLAU, Jairo e PEIXOTO, Vitor. (2007), "As bases municipais da votação de Lula em 2006" [electronic version]. Fórum Nacional - Instituto Nacional de Altos Estudos - Disponível em https://www.academia.edu/1863106/As_bases_ municipais_da_vota\%C3\%A7\%C3\%A3o_de_ Lula_em_2006.

NORPOTH, Helmut; LEWIS-BECK, Michael S. \& LAFAY, Jean-Dominique. (1991), Economics and politics: the calculus of support. Ann Arbor, University of Michigan Press.

PATEMAN, Carole. (1970), Participation and democratic theory, Cambridge. Cambridge University Press.

PEIXOTO, Vitor \& RENNÓ, Lucio. (2011), "Mobilidade social ascendente e voto: as eleições presidenciais de 2010 no Brasil”. Opinião Pública, 17: 304-332.

PORTO, Mauro P. (2007), "Framing Controversies: television and the 2002 presidential election in Brazil”. Political Communication, 24 (1): 19-36.
REESE, Stephen D.; GANDY, Oscar H. \& GRANT, August E. (2001), Framing public life : perspectives on media and our understanding of the social world. Mahwah, NJ, Lawrence Erlbaum Associates.

RUBIM, Antonio Albino Canelas e AZEVEDO, Fernando Antonio. (1998), "Mídia e política no Brasil: textos e agenda de pesquisa". Lua Nova: Revista de Cultura e Politica: 189-216.

SNIDERMAN, P. \& LEVENDUSCKY, Matthew. (2008), "An institutional theory of political choice", in Russell Dalton e Hans-Dieter Klingemann (orgs.), The Oxford Handbook of Political Behavior, Oxford University Press.

SOROKA, Stuart N.; STECULA, Dominik A. \& WLEZIEN, Christopher. (2015), "It's (change in) the (future) economy, stupid: economic indicators, the media, and public opinion". American Journal of Political Science, 59 (2): 457-474.

SU, Lishan. (2008). Impacts of mass media coverage of the economy during normal times and recessions on the Index of consumer confidence using time series analysis and granger causal analysis, Iowa State University.

TUFTE, Edward R. (1975), "Determinants of the outcomes of midterm congressional Elections". The American Political Science Review, 69 (3): 812-826.

VEIGA, Luciana Fernandes \& ROSS, Steven Dutt. (2016), "Os determinantes da avaliação da economia na eleição presidencial brasileira em 2014”. Opiniáo Pública, 22: 524-549.

ZALLER, J. (2004), "Floating voters in US presidential elections, 1948-2000", in Willem E. Saris e Paul M. Sniderman (orgs.), Studies in public opinion: attitudes, nonattitudes, measurement error, and change, Princeton, NJ, Princeton University Press.

ZUCCO, Cesar. (2008), “The president's 'new' constituency: Lula and the pragmatic vote in Brazil's 2006 presidential elections". Journal of Latin American Studies, 40 (1): 29-49.

ZUCCO, Cesar. (2013), "When payouts pay off: conditional cash transfers and voting behavior in Brazil 2002-10". American Journal of Political Science, 57 (4): 810-822. 


\section{O OVO E A GALINHA: ESTUDO DO ENQUADRAMENTO E DA RECEPÇÃO DA COBERTURA JORNALÍSTICA NO PLEITO DE 2014} João Feres Júnior, Luciana Fernandes
Veiga e Ednaldo Ribeiro

Palavras-chave: Voto econômico; Cobertura da grande imprensa; Enquadramento midiático; Recepçáo de notícia; Eleição presidencial no Brasil 2014

A partir de uma revisão dos trabalhos sobre o voto econômico e a cobertura da imprensa em eleições, propomos a hipótese de que o enquadramento (com noçôes de valência e responsabilização dos eventos) impresso pelo veículo em sua cobertura está associado à percepção do leitor/eleitor sobre a economia e o desempenho do governo federal. Fazemos uma análise quantitativa do enquadramento da economia e do governo federal nas notícias dos seguintes veículos: Folha de $S$. Paulo, O Estado de S. Paulo, O Globo e Jornal Nacional, entre os meses de agosto e outubro de 2014. Utilizamos um survey com os dados sobre as percepçóes da situaçâo da economia e do governo federal de consumidores de tais jornais e telejornal, no período. A partir de modelos logísticos multinomiais, concluímos que assistir $J N$ e ler $O$ Globo reduzem as chances de avaliar bem a economia, mas não impactam na avaliação do governo; ler a FSP não altera tais chances.

\section{THE EGG AND THE CHICKEN ANALOGY: STUDY OF THE FRAMEWORK AND RECEPTION OF JOURNALISTIC COVERAGE IN THE 2014 ELECTIONS}

\author{
João Feres Júnior, Luciana Fernandes \\ Veiga and Ednaldo Ribeiro
}

Keywords: Economic vote; Coverage of the major press; Media coverage; News reception; Presidential election in Brazil in 2014

Starting from a critical review of the literature on the economic vote, on the one hand, and on news media coverage in electoral periods, on the other hand, we propose a study that combines the analysis of the content of journalistic texts the perceptions of media consumers. Our analysis combines the emission and the reception of news content. We propose the hypothesis that the framework (with notions of valence and accountability of events) printed by the vehicle in its coverage is associated with the reader / voter's perception of the economy and the performance of the federal government. First, it was conducted a quantitative analysis of the economic and federal government framework in the news published by Folha de S. Paulo, O Estado de S. Paulo, O Globo and Jornal Nacional, from August to October 2014. Next, we selected data on perceptions of the state of the economic and the Federal Government of consumers of these media during the same period. Applying multinomial logistic models, and using government satisfaction and economy valuation as dependent variables, we conclude that that being an audience of Jornal Nacional and being a reader of $O$ Globo reduce the chances of evaluating the economy well, but do not directly impact the evaluation of the Federal Government, while being a Folha de S. Paulo reader does not alter the chances of evaluating the economy and the Federal Government.

\section{L'EUF ET LA POULE : ÉTUDE \\ DE L'ENCADREMENT ET \\ DE LA RÉCEPTION DE LA COUVERTURE MÉDIATIQUE DES ÉLECTIONS DE 2014}

\section{João Feres Júnior, Luciana Fernandes Veiga et Ednaldo Ribeiro}

Mots-clés: Vote économique; Couverture médiatique de masse; Encadrement médiatique; Réception de l'information; Élection présidentielle brésilienne de 2014.

Partant d'une analyse des travaux sur le vote économique et la couverture médiatique d'élections, nous formulons l'hypothèse que l'encadrement (avec des notions de valence et de responsabilisation des événements) imprimé par les médias dans leur couverture est associé à la perception que le lecteur/électeur a de l'économie et de la compétence du gouvernement fédéral. Pour ce faire, nous avons procédé à une analyse quantitative de l'encadrement de l'économie et du gouvernement fédéral d'août à octobre 2014 dans les médias suivants: les journaux imprimés Folha de Sáo Paulo, O Estado de São Paulo, O Globo etle journal télévisé Jornal Nacional. Nous avons utilisé une enquête comportant des données sur les perceptions de la situation de l'économie et du gouvernement fédéral de consommateurs de ces médias. Le recours à des modèles logistiques multinomiaux nous a permis de conclure que regarder le Jornal Nacional et lire O Globo réduisent les chances de bien évaluer l'économie mais n'ont pas d'impact sur l'évaluation du gouvernement; par contre, lire le Folha de São Paulo n'influence pas l'évaluation des lecteurs. 